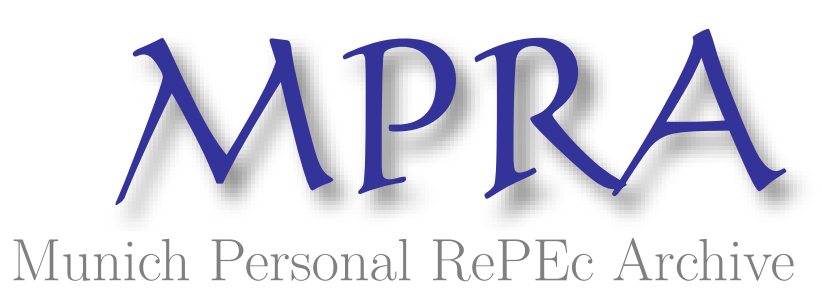

\title{
A Theory of Linkage between Monetary Policy and Banking Failure in Developing Countries
}

\author{
Cadet, Raulin Lincifort \\ Université de Rennes 1
}

December 2006

Online at https://mpra.ub.uni-muenchen.de/5497/

MPRA Paper No. 5497, posted 30 Oct 2007 UTC 


\title{
A Theory of Linkage between Monetary Policy and Banking Failure in Developing Countries*
}

\author{
Raulin Lincifort Cadet $^{\dagger}$ \\ First version: December 2006 \\ Current version: October 2007
}

\begin{abstract}
This paper presents a model of the banking sector that maximize profit and an individual bank which is a price taker, in a developing country. The interest rate on treasury bills is included in the model to measure monetary policy. The mathematical expression of the probability of banking failure is calculated; And, I show that, in developing countries, a tightening monetary policy may induce efficient banking failure.
\end{abstract}

Keywords: Banking Failure, Monetary Policy, Interest Rate, Developing Countries

JEL classifications: G21, G33, E52

\footnotetext{
*The author is grateful to Xavier Freixas, Jean-Jacques Durand, Christophe Tavéra, Marc Baudry, Gilles Canales, and Steeve Crittenden for helpful discussion and comments. He wishes to thank the seminar participants at the CREM, in April 2007, and the participants at the IBFR Conference on Business and Finance, in May 2007, for their comments. The opinions expressed in this paper are those of the author. They do not necessarily reflect those of the CREM and the CREGED.

${ }^{\dagger}$ Center for Research in Economics and Management (CREM-CNRS UMR6211), Rennes 1 University (France) - Center for Research in Management and Development Economics (CREGED), Quisqueya University (Haiti)

Corresponding author: Raulin Lincifort Cadet - Centre de Recherche en Economie et Management (CREM), Université de Rennes 1 - 7, Place Hoche - CS 86514, 35065 Rennes Cedex, France - E-mail address: raulin.cadet@univ-rennes1.fr;
} 


\section{Introduction}

Some empirical and theoretical papers study the causes of banking crisis. Empirical studies emphasize the role of the banks conditions as principal factors. Wheelock and Wilson [13] find that bank specific data are significant factors of US bank failures and acquisitions. Arena [1], for instance, reveals that banklevel fundamentals significantly affect banking failure in East Asia and in Latin America. About the macroeconomic conditions, one of the factors of banking crises mentioned by Mishkin [9] is high interest rates.

Kraft and Galac [8] analyze deposit interest rates and banking failure that become high because of liberalization and competition in Croatia. Actually, in addition of liberalization and competition, a tightening monetary policy may induce increasing of interest rates. Some researchers analyze the way monetary policy affects balance sheets and the behavior of banks. For instance, Kashyap and Stein [7] examine the impact of monetary policy on bank's balance sheets. Bolton and Freixas [3] analyze the effects of monetary policy on securities market and bank lending. These papers, however, do not analyze the impact of monetary policy on banking failure. To my knowledge, no other paper presents a theoretical framework of linkage between monetary policy and banking failure.

This paper fill this gap; I show that, in developing countries, a tightening monetary policy may induce efficient banking failure. Hancock [6] and Goyeau et al. [5] analyze bank profitability and interest rates. But, they do not analyze banking failure. Even if there is a link between profitability and solvency, they are different. A bank may be solvent in spite of making losses, if equity is still positive. The empirical results of Goyeau et al. [5] reveal that a decrease of interest rate in Europe has a negative effect on some banking systems whereas some other banking systems still profit. However, according to Hancock [6] bank profit appears to increase with interest rate, which contradicts Goyeau et al. [5]. Thus, the question still remains for research: Does bank profitability increase when interest rates are raised? If some banks profit from interest rates increasing whereas some other banks do not, what can explain this difference?

Beyond these questions, this paper is more concerned about the followings: Is the impact of a tightening monetary policy on banking failure identical for all banks? If there is a difference, what explains it? I show that a tightening monetary policy, in developing country, may induce efficient banking failure. Regarding firms, one of the main findings of Bernanke and Gertler [2] is that a shortage of money, which increases interest rates, reduces their net worth. However, there is no theoretical framework about the linkage between monetary policy and individual banking failure. Those questions are essential, as banking failure has economic and social consequences.

The model presented in this paper show that a tightening monetary policy may induce efficient banking failure, in developing country. Actually, the model shows also that an efficient bank profit from a tightening monetary policy, whereas an inefficient bank does not. Thus, only inefficient banks should fail because of a tightening monetary policy, in developing country. The paper is organized as follows: after this introduction, the second section presents the 
model, and the third one exposes some concluding remarks.

\section{The Model}

This section presents a model of the banking sector that maximize profit and an individual bank which is a price taker. In this model, prices are interest rates on treasury bills, loans, and deposits. All interest rates are determined by the banking market, except interest rate on treasury bills. I show that, in developing countries, a tightening monetary policy may induce banking failure.

\subsection{The Banking Sector}

I assume that the banking sector is a competitive market. Secondary market is not included in the model, because I consider developing countries, where the secondary market is not well developed or does not exist at all. The banking sector has three assets: loans $\left(\sum L\right)$, treasury bills $\left(\sum B\right)$, and reserve $\left(\sum R\right)$. In the liability side of the sector's balance sheet there are the shareholders equity $\left(\sum K\right)$ and deposits $\left(\sum D\right)$. The reserve of the banking sector is a proportion of deposits. The reserve rate is denoted $\alpha$. Central bank requires from the banking sector a capital adequacy which should be superior or equal to a proportion of risk-weighted assets (denoted $\phi$ ) .

Reserve:

$$
\sum R=\alpha \sum D
$$

Capital requirement:

$$
\phi\left(\sigma_{l} \sum L+\sigma_{b} \sum B\right) \leq \sum K
$$

$\sigma_{l}$ and $\sigma_{b}$ are the risk-weight of loans and treasury bills, respectively. It is assumed that the risk-weight of loans is identical for all banks. Because treasury bills are risk-free, $\sigma_{b}=0$. Thus, the capital requirement inequality becomes:

$$
\phi \sigma_{l} \sum L \leq \sum K
$$

The balance sheet identity:

$$
\sum L+\sum B+\sum R=\sum K+\sum D
$$

In the balance sheet identity (equation 3$)$, I replace reserve $\left(\sum R\right)$ by its value from equation 1. It is assumed that all banks maintain the shareholders equity equal to the minimum of capital requirement, $\phi \sigma_{l} \sum L .{ }^{1}$ Thus, $\sum K$ is replaced

\footnotetext{
${ }^{1}$ One of the propositions proved by Rochet [10] is that under deposit insurance, commercial bank's optimal behavior is to maintain capital just sufficient for meeting capital requirement. However, in developing countries, there is implicit deposit insurance.
} 
by its value also.

$$
\begin{array}{r}
\sum L+\sum B+\alpha \sum D=\phi \sigma_{l} \sum L+\sum D \\
\sum L\left(1-\phi \sigma_{l}\right)+\sum B=\sum D(1-\alpha) \\
\sum B=\sum D(1-\alpha)-\sum L\left(1-\phi \sigma_{l}\right)
\end{array}
$$

The profit function of the sector is the following:

$$
\sum \pi=r_{l}(1-\bar{p}) \sum L+r_{b} \sum B-r_{d} \sum D-\gamma_{l} \sum L-\gamma_{d} \sum D-\bar{p} \sum L
$$

The interest rates on loans, deposits, and treasury bills are respectively $r_{l}$, $r_{d}$, and $r_{b}$. The expected default rate of the banking sector is denoted $\bar{p}$, and the marginal costs of loans and deposits are respectively $\gamma_{l}$ and $\gamma_{d}$. Marginal costs are assumed to be constants. All banks face the same marginal costs whereas the default rate, $p$, differs from bank to bank. ${ }^{2}$ As interest rate on treasury bills is used as instrument of monetary policy in most developing countries, it is used in this model as the indicator of monetary policy.

If equation 4 is replaced in the profit function, it becomes:

$$
\begin{gathered}
\sum \pi=r_{l}(1-\bar{p}) \sum L+r_{b}(1-\alpha) \sum D-r_{b}\left(1-\phi \sigma_{l}\right) \sum L \\
-r_{d} \sum D-\gamma_{l} \sum L-\gamma_{d} \sum D-\bar{p} \sum L
\end{gathered}
$$

Proposition 1 The interest rates on loans and deposits are positive functions of interest rate on treasury bills, and the costs of intermediation increases the first one and decrease the second.

Proof: The problem of the banking sector is to maximize profit. To resolve it, banking sector chooses the optimal amounts of loans and deposits. Thus, the condition of first order is the following:

$$
\begin{gathered}
\frac{\partial \sum \pi}{\partial \sum L}=r_{l}(1-\bar{p})-r_{b}\left(1-\phi \sigma_{l}\right)-\gamma_{l}-\bar{p}=0 \\
r_{l}=\frac{1}{1-\bar{p}}\left[r_{b}\left(1-\phi \sigma_{l}\right)+\gamma_{l}+\bar{p}\right] \\
\frac{\partial \sum \pi}{\partial \sum D}=r_{b}(1-\alpha)-r_{d}-\gamma_{d}=0 \\
r_{d}=r_{b}(1-\alpha)-\gamma_{d}
\end{gathered}
$$

Equation 7 shows that the risk-weighted capital requirement, $\phi \sigma_{l}$, reduces interest rates on loans, whereas equation 8 indicates that the reserve rate, $\alpha$, reduces interest rate on deposits. Capital requirement constitute a cost supported by banks, as it restricts the bank to provide loans to a certain extent.

\footnotetext{
${ }^{2}$ The default rate is the ratio of loans not reimburse to total loans.
} 
Zarruk and Madura [14] find a similar result. The model develop in their paper shows that capital regulation results in a reduced interest margin.

The reserve rate, $\alpha$, which is equal or superior to the rate of reserve requirement, is also a cost, as banks do not get return from it. This cost is reported to the depositors. Indeed, the interest rate paid to depositors is inferior to what it should be if there was not any reserve in the assets of the banks. Regarding the costs of financial intermediation, only the customers support them. These costs reduce interest rate they should receive on deposits, and increase what they should pay on loans. In addition, the expected default rate is added to the interest rate that banks'customers paid on loans.

\subsection{An Individual Bank}

In this subsection, a bank profit and its probability of failure are modeled. All variables are used without the sum symbol in order to indicate that only one bank is considered instead of the banking sector. The bank is a price taker. Thus, interest rates received on loans and paid on deposits are those determined by the market (equations 7 and 8 ), whereas the value of the interest rate on treasury bills is decided by central bank. The default rate of the bank is $p$. The managers of the bank know the true value of $p$ when it is realized. This subsection models the individual bank as follows:

Reserve:

$$
R=\alpha D
$$

Capital requirement:

$$
\phi \sigma_{l} L \leq K
$$

The balance sheet identity:

$$
L+B+R=K+D
$$

In the balance sheet identity, reserve $(R)$ is replaced by its value from equation 9 , and $K$ by its value from equation $10 .^{3}$

$$
\begin{array}{r}
L+B+\alpha D=\phi \sigma_{l} L+D \\
L\left(1-\phi \sigma_{l}\right)+B=D(1-\alpha) \\
B=D(1-\alpha)-L\left(1-\phi \sigma_{l}\right)
\end{array}
$$

The profit function of the bank is written as follows:

$$
\pi=r_{l}(1-p) L+r_{b} B-r_{d} D-\gamma_{l} L-\gamma_{d} D-p L
$$

\footnotetext{
${ }^{3}$ Remember that it is assumed that all banks maintain the exact minimum of capital requirement.
} 
In the profit function (equation 12), interest rates on loans and deposits are replaced by their respective value which are in equations 7 and 8 . Thus, the profit function of the bank becomes ${ }^{4}$ :

$$
\pi=\frac{\bar{p}-p}{1-\bar{p}} L\left[1+\left(1-\phi \sigma_{l}\right) r_{b}+\gamma_{l}\right]
$$

The gap between the expected default rate of the banking sector and the default rate of an individual bank, $\bar{p}-p$, is the relative efficiency of this bank.

Proposition 2 When central bank tightens monetary policy, by increasing interest rate on treasury bills, depending on bank's relative efficiency, three cases are possible, regarding profit.

Proof: The partial derivative of the profit function of the bank, with respect to interest rate on treasury bills, is the following:

$$
\frac{\partial \pi}{\partial r_{b}}=\frac{\bar{p}-p}{1-\bar{p}} L\left(1-\phi \sigma_{l}\right)
$$

1. If the relative efficiency of the bank is negative, i.e, $\bar{p}-p<0$, a tightening of monetary policy will increase the bank's losses.

$$
\frac{\partial \pi}{\partial r_{b}}<0
$$

2. If the relative efficiency of the bank is null, i.e, $\bar{p}-p=0$, a shock of monetary policy will have no impact on the profits of the bank.

$$
\frac{\partial \pi}{\partial r_{b}}=0
$$

3. If the relative efficiency of the bank is positive, i.e, $\bar{p}-p>0$, its profits will increase when central bank tightens monetary policy.

$$
\frac{\partial \pi}{\partial r_{b}}>0
$$

Proposition 3 An increase of interest rate on treasury bills which is a restrictive monetary policy increases the probability of failure of the bank.

Proof: I consider that a bank fails when it is insolvent. Thus, the bank is insolvent if the sum of shareholders equity and profit is negative. The probability of failure of the bank, which is denoted $\rho$, is calculated as follows:

$$
\begin{array}{r}
\rho=P(K+\pi<0)=P(\pi<-K) \\
\rho=P\left(\frac{\bar{p}-p}{1-\bar{p}} L\left[1+\left(1-\phi \sigma_{l}\right) r_{b}+\gamma_{l}\right]<-K\right) \\
\rho=P\left(\bar{p}-p<-\frac{K}{L} \frac{1-\bar{p}}{1+\left(1-\phi \sigma_{l}\right) r_{b}+\gamma_{l}}\right)
\end{array}
$$

\footnotetext{
${ }^{4}$ See appendix for details about calculus.
} 
Equation 15 shows that the probability of failure is the probability that the relative efficiency is inferior to a threshold which is denoted T, with:

$$
T=-\frac{K}{L} \frac{1-\bar{p}}{1+\left(1-\phi \sigma_{l}\right) r_{b}+\gamma_{l}}
$$

Thus, the probability of the failure of the bank, $\rho$, is:

$$
\rho=P(\bar{p}-p<T)
$$

The gap between the expected default rate of the banking sector and the default rate of the individual bank is defined by the interval $I=[-1,1]$. It is assumed that this gap is distributed as a uniform law. Thus, the probability can be approximated as follows ${ }^{5}$ :

$$
\begin{gathered}
\rho=P(\bar{p}-p<T) \approx P(-1 \leq \bar{p}-p \leq T) \\
\rho=\frac{T-(-1)}{1-(-1)}=\frac{1}{2}(T+1) \\
\rho=-\frac{K}{2 L} \frac{1-\bar{p}}{1+\left(1-\phi \sigma_{l}\right) r_{b}+\gamma_{l}}+\frac{1}{2}
\end{gathered}
$$

The partial derivative of the probability of failure can now be calculated with respect to interest rate on treasury bills.

$$
\frac{\partial \rho}{\partial r_{b}}=\frac{K}{2 L} \frac{\left(1-\phi \sigma_{l}\right)(1-\bar{p})}{\left[1+\left(1-\phi \sigma_{l}\right) r_{b}+\gamma_{l}\right]^{2}}>0
$$

This last result (equation 17) indicates that an increase of interest rate on treasury bills, i.e, a restrictive monetary policy, increases the probability of banking failure. This increase is identical to the increase of probability that the relative efficiency of a bank is inferior to the threshold, $T$. The probability of banking failure increases after an increase of interest rate. Actually, I show that the increasing of interest rate induces a decrease in relative efficiency of the bank. When interest rates are high, risk averse agents prefer not to invest. However, riskier agents are more willing to pay higher interest rates. Because most of the agents that supply loans are the riskiest, banks tend to select a high proportion of borrowers among them.

Proposition 4 An efficient bank decreases its loan portfolio to reduce its probability of failure when central bank tightens monetary policy.

Proof: I make the proof by calculating the impact of a variation of loans on the probability of banking failure.

\footnotetext{
${ }^{5}$ This approximation implies that it is implicitly assumed that a bank is insolvent not only when its net worth is negative, but also when it is null.
} 


$$
\frac{\partial \rho}{\partial L}=\frac{K}{2 L^{2}}\left[\frac{1-\bar{p}}{1+\left(1-\phi \sigma_{l}\right) r_{b}+\gamma_{l}}\right]>0
$$

The equation 18 shows that an increase of loans increases the probability of bank failure. The inverse was true: a decrease of loans reduces the probability of banking failure. Thus, when central bank tightens monetary policy, an efficient bank should decrease loans enough to decrease its probability of failure. However, the probability of failure of inefficient banks that do not decrease loans enough, after a tightening monetary policy, should increase. This is concurrent with Caprio and Klingebiel [4] which reveal that one of principal causes of bank insolvency is inefficient lending. It is also concurrent with Stein [12] which argues that only "Good" banks lend less after a fall of insured deposits.

The finding of Romer and Romer [11], nevertheless, differs from mine. Romer and Romer [11] conclude that banks can use other financial sources to raise funds and maintain loans at the same level when there is a shock to insured deposits. Because the model I develop concerns developing countries, it is implicitly assumed that there is not any alternative financial source. Actually, in developing countries, sources for raising funds are limited. In addition, interest rates and asymmetric information are usually high even before a shock of monetary policy, in developing countries, which is not the same situation in developed countries.

A limitation of my model is that it does not account for time, which limited the possibility to show the dynamic impact of monetary policy on banking failure. Although static, the model meet the questions to which it intended to answer; The model shows that the impact of a tightening monetary policy on the probability of failure was not the same for all banks. In addition, it showed the reason of this difference.

\section{Concluding Remarks}

The main result of the model is that a tightening monetary policy, in developing countries, induces efficient banking failure. Unlike inefficient banks, efficient banks profit from a tightening monetary policy. The model shows that a tightening of monetary policy causes failure of inefficient banks. Thus, in developing countries, a tightening monetary policy, contributes to clean up the banking system. It is efficient to eliminate bad banks in the banking sector. When a tightening monetary policy induces banking failure of bad banks, it is an efficient banking failure.

The model shows that some banks may profit from increasing of interest rates whereas some other banks do not. The level of relative efficiency explained this difference. Actually, a tightening monetary policy reduces the relative efficiency of an individual bank. And the probability that the relative efficiency of a bank is within the interval corresponding to failure, increases when central bank tightens monetary policy. But, an efficient bank reduces its loan portfolio enough 
to stabilize its level of relative efficiency and its probability of failure. Thus, only inefficient banks should fail because of a tightening monetary policy; A tightening monetary policy induces efficient banking failure that clean up the banking sector.

One of the implication of my model is that inefficient small banks become more vulnerable to failure than inefficient big banks, when central bank tightens monetary policy. Actually, big banks can invest in international markets easier than small banks. Thus, they have more alternative choices than small banks. Because their choices is narrow, small banks become more vulnerable to failure after a tightening of monetary policy. In addition, loan portfolio of banks can not be null; There is a threshold of interest rate, which I call a threshold of crisis, that interest rate on treasury bills should not exceed. If the interest rate exceeds this threshold of crisis, efficient small banks will fail. And, even efficient big banks may fail, and systemic banking crisis may happen, depending on how high the interest rate exceeds the threshold. Thus, in developing countries, a tightening monetary policy induce efficient banking failure if interest rate on treasury bills is equal to the threshold of crisis at most. Extended research will analyze how monetary policy affect banking failure in developed countries.

\section{A Calculus of the Profit Function of the bank}

The profit function of the bank is written as follow:

$$
\pi=r_{l}(1-p) L+r_{b} B-r_{d} D-\gamma_{l} L-\gamma_{d} D-p L
$$

In the profit function (equation 19) I replace interest rates on loans and deposits by their respective value which are in equations 7 and 8 . Thus, the profit function of the bank becomes:

$$
\begin{gathered}
\pi=\frac{1}{1-\bar{p}}\left(r_{b}-r_{b} \phi \sigma_{l}+\gamma_{l}+\bar{p}\right)(1-p) L+r_{b}(1-\alpha) D-r_{b}\left(1-\phi \sigma_{l}\right) L \\
-r_{b}(1-\alpha) D+\gamma_{d} D-\gamma_{l} L-\gamma_{d} D-p L \\
\pi=\frac{1}{1-\bar{p}}\left[r_{b} L-r_{b} \phi \sigma_{l} L+\gamma_{l} L+\bar{p} L-r_{b} p L+r_{b} \phi \sigma_{l} p L-\gamma_{l} p L-\bar{p} p L\right. \\
\left.-r_{b}\left(1-\phi \sigma_{l}\right)(1-\bar{p}) L-\gamma_{l}(1-\bar{p}) L-p(1-\bar{p}) L\right] \\
\pi=\frac{1}{1-\bar{p}}\left[r_{b} L-r_{b} \phi \sigma_{l} L+\gamma_{l} L+\bar{p} L-r_{b} p L+r_{b} \phi \sigma_{l l} p L-\gamma_{l} p L-\bar{p} p L\right. \\
\left.-r_{b} L+r_{b} \bar{p} L+r_{b} \phi \sigma_{l} L-r_{b} \phi \sigma_{l} \bar{p} L-\gamma_{l} L+\gamma_{l} \bar{p} L-p L+\bar{p} p L\right]
\end{gathered}
$$




$$
\begin{gathered}
\pi=\frac{1}{1-\bar{p}}\left[L(\bar{p}-p)+r_{b} L(\bar{p}-p)-r_{b} \phi \sigma_{l} L(\bar{p}-p)+\gamma_{l} L(\bar{p}-p)\right] \\
\pi=\frac{\bar{p}-p}{1-\bar{p}} L\left[1+\left(1-\phi \sigma_{l}\right) r_{b}+\gamma_{l}\right]
\end{gathered}
$$

\section{References}

[1] Arena, M. 2007. Bank failure and bank fundamentals: A comparative analysis of Latin America and East Asia during the nineties using bank-level data. Journal of Banking and Finance In press.

[2] Bernanke, B. and Gertler, M. 1989. Agency costs, net worth, and business fluctuations. The American Economic Review 79, 14-31.

[3] Bolton, P. And Freixas, X. 2006. Corporate finance and the monetary transmission mechanism. Review of Financial Studies 19, 829-870.

[4] Caprio, G. And Klingebiel, D. 1997. Bank insolvency, bad luck, bad policy, or bad banking? In Annual World Bank Conference on Development Economics, M. Bruno and B. Pleskovic, Eds. The World Bank, Washington, D.C.

[5] Goyeau, D., Sauviat, A., And Tarazi, A. 2002. Rentabilité bancaire et taux d'intérêt de marché: une application aux principaux systèmes bancaires européens sur la période 1988-1995. Revue d'Economie Politique 112, 2, 275291.

[6] HANCOCK, D. 1985. Bank profitability, interest rates, and monetary policy. Journal of Money, Credit, and Banking 17, 2, 189-202.

[7] Kashyap, A. K. and Stein, J. C. 1995. The impact of monetary policy on bank balance sheet. Carnegie-Rochester Conference Series on Public Policy 42, 151-195.

[8] Kraft, E. and Galac, T. 2007. Deposit interest rates, asset risk and bank failure in Croatia. Journal of Financial Stability 2, 312-336.

[9] Mishrin, F. S. 1999. Global financial instability: Framework, events, issues. The Journal of Economic Perspectives 13, 4, 3-20.

[10] Rochet, J. C. 2004. Capital requirements and the behavior of commercial banks. In Credit, Intermediation and the Macroeconomy: Models and Perspectives. Oxford University Press, Oxford.

[11] Romer, C. D. And Romer, D. H. 1990. New evidence on the monetary transmission mechanism. In Brookings Papers on Economic Activity, W. C. Brainard and G. L. Perry, Eds. Washington, D.C., 149-213. 
[12] Stein, J. C. 1998. An adverse-selection model of bank asset and liability management with implications for the transmission of monetary policy. Rand Journal of Economics 2, 3, 466-486.

[13] Wheelock, D. C. And Wilson, P. W. 2000. Why do banks disappear: the determinants of U.S. bank failures and acquisitions. Review of Economics and Statistics, 127-138.

[14] Zarruk, E. R. ANd Madura, J. 1992. Optimal bank interest margin under capital regulation and deposit insurance. Journal of Financial and Quantitative Analysis 27, 1 (March), 143-149. 